\title{
The effect of chain extender structure on the properties of new thermoplastic poly(carbonate-urethane)s derived from MDI
}

\author{
Magdalena Rogulska $^{1}$ (1) Anna Kultys ${ }^{1} \cdot$ Stanisław Pikus $^{2}$
}

Received: 12 April 2016/Accepted: 30 July 2016/Published online: 17 August 2016

(c) The Author(s) 2016. This article is published with open access at Springerlink.com

\begin{abstract}
Two series of high-molar-mass thermoplastic poly(carbonate-urethane)s (PCURs) were synthesized from nonconventional sulfur-containing chain extenders, i.e., $2,2^{\prime}$-[sulfanediylbis(benzene-1,4-diyloxy)]diethanol (diol SE) and 2,2'-[methanediylbis(benzene-1,4-diylmethanediylsulfanediyl)]diethanol (diol ME), 1,1'-methanediylbis(4-isocyanatobenzene) and 30, 45 and $60 \mathrm{~mol} \%$ aliphatic polycarbonate diol of $M_{\mathrm{n}}=2000 \mathrm{~g} \mathrm{~mol}^{-1}$ (Desmophen ${ }^{\circledR}$ C2200, Bayer) via a one-step melt polyaddition. The PCURs were investigated by FTIR, UV-Vis, atomic force microscopy, X-ray diffraction analysis, differential scanning calorimetry, thermogravimetry (TG) and TG-FTIR. Moreover, their Shore A/D hardness, tensile, adhesive and optical properties were determined. The obtained PCURs were transparent or opaque elastomers, possessing amorphous or partially crystalline structures. The polymers based on diol ME showed lower glass transition temperatures $\left(-9\right.$ to $(-8)$ vs. -7 to $\left.20^{\circ} \mathrm{C}\right)$ and better microphase separation. All the PCURs exhibited a relatively good thermal stability. Their temperature of $1 \%$ mass loss was within the range of $284-292{ }^{\circ} \mathrm{C}$ with somewhat higher values shown by those obtained from diol ME. The PCURs decomposed in two (from diol ME) or three (from diol SE) stages, and for both types of polymers, the main decomposition occurred at the first stage. All the PCURs based on
\end{abstract}

Magdalena Rogulska

mrogulska@umcs.lublin.pl

1 Department of Polymer Chemistry, Faculty of Chemistry, Maria Curie-Skłodowska University, ul. Gliniana 33, 20-614 Lublin, Poland

2 Department of Crystallography, Faculty of Chemistry, Maria Curie-Skłodowska University, Pl. Marii Curie-Skłodowskiej 3, 20-031 Lublin, Poland diol SE exhibited higher tensile strength (33.5-41.9 vs. 27.0-31.5 MPa), but smaller elongation at break (300-400 vs. 450-550 \%) than polymers derived from diol ME. Somewhat better adhesive properties and a slightly higher refractive index were found for polymer based on diol ME with two sulfur atoms.

Keywords Sulfur-containing thermoplastic elastomers . Aliphatic-aromatic chain extenders - Polycarbonate soft segment $\cdot$ DSC . Thermogravimetry $\cdot$ Mechanical properties

\section{Introduction}

Thermoplastic polyurethane elastomers (TPUs) are interesting materials due to the set of useful properties which can be varied by the choice of their structural units. The basic reagents used for TPUs synthesis, which are multiblock copolymers, are diisocyanates and short-chain diols that build hard segments, and long-chain diols that constitute soft segments. The hard segments particularly affect the modulus, hardness and tear strength, whereas the soft segments provide flexibility, softness and low-temperature resistance $[1,2]$.

Conventional TPUs are synthesized from polyether, polyester or polycarbonate diols (PCDs). TPUs based on PCDs, which are relatively new ones, have at the same time a high resistance to heat, hydrolysis and oxidation in comparison with TPUs derived from polyether and polyester diols [3-5]. The main diisocyanate used is $1,1^{\prime}$-methanediylbis(4isocyanatobenzene) (MDI). Among aliphatic diols, the usual chain extenders, mainly butane-1,4-diol (BD) produces TPUs with the best mechanical properties. Applying aliphatic- 
aromatic and aromatic "bulky" diols, i.e., 2,2'-(benzene-1,4diyldioxy)diethanol, hard elastomers with high modulus of elasticity are obtained [2], while from bisphenols, such as bisphenol-S, bisphenol-A, bisphenol-AF, one gets polymers at the same time with enhanced thermal stability. Introducing additionally bromine atoms into the structure of these bisphenols results in improved flame retardancy of the resulting polymers [6]. In turn, the use of mesogenic diols, including derivatives of biphenyl, benzophenone and azobenzene, facilitates obtaining polymers with liquid-crystalline properties [7].

This paper is a continuation of our studies on the synthesis and characterization of new thermoplastic segmented polyurethanes, including TPUs, based on commercial diisocyanates and polymer diols as well as nonconventional aliphatic-aromatic chain extenders. These chain extenders are diols with sulfide linkages and dithiols, derivatives, among others, of diphenylmethane, diphenylethane, benzophenone, diphenyl ether and diphenyl sulfide [8-18]. Making use of "bulky" chain extenders, additionally introducing sulfur atoms to polymer chain can improve adhesive properties to metals $[9,10,13,17,18]$ and refractive index [10,13] and enhance antimicrobial activity [10] of such polyurethanes in relation to conventional ones.

Herein, we determined the structure and some properties of new thermoplastic poly(carbonate-urethane)s (PCURs) derived from diol containing one diaryl-sulfide linkage, i.e., 2,2'-[sulfanediylbis(benzene-1,4-diyloxy)]diethanol (diol SE), or diol containing two dialkyl-sulfide linkages, i.e., 2,2'[methanediylbis(benzene-1,4-diylmethanediylsulfanediyl)] diethanol (diol ME), MDI and 30, 45 and $60 \mathrm{~mol} \%$ aliphatic PCD of $M_{\mathrm{n}}=2000 \mathrm{~g} \mathrm{~mol}^{-1}$ (Desmophen ${ }^{\circledR} \mathrm{C} 2200$, Bayer). Both diol SE and ME can be obtained in a simple manner and with high yield. Moreover, because of their low melting temperatures $\left(T_{\mathrm{m}} \mathrm{s}\right)$, melt polyaddition could be used to produce high-molar-mass polymers at relatively low reaction temperatures. These chain extenders have already been applied by us for the synthesis of MDI-based PCURs by using poly(hexane-1,6-diyl carbonate) diol (PHCD) of $M_{\mathrm{n}}=860 \mathrm{~g} \mathrm{~mol}^{-1}[12,18]$. Most of the obtained polymers showed high tensile strengths (42.0-55.8 MPa), but unfortunately were not elastomers (their glass transition temperatures $\left(T_{\mathrm{g}} \mathrm{s}\right)$ were in the range of $16.2-47.0^{\circ} \mathrm{C}$ ). The purpose of our work was to check the possibility of obtaining TPUs by applying a PCD of higher molar mass and determining to what extent the structure of the chain extenders we used influences the properties of the resulting PCURs. For all the PCURs physicochemical, thermal and mechanical properties were determined and for selected ones, also transparency, refractive index and adhesive properties.

\section{Experimental}

\section{Materials}

The diol SE (m.p. $=101-102{ }^{\circ} \mathrm{C}$ after recrystallization first from methanol/water and next from 1,2-dichloroethane) was prepared from $4,4^{\prime}$-sulfanediyldiphenol and ethylene carbonate by a modified procedure described by Penczek and al. [19], while the diol ME (m.p. = 77-78 ${ }^{\circ} \mathrm{C}$ ) was obtained by the condensation reaction of (methanediyldibenzene-1,4diyl)dimethanethiol with 2-chloroethanol in $10 \%$ aqueous solution of sodium hydroxide [12]. PCD (Desmophen ${ }^{\circledR}$ C2200) of $\bar{M}_{\mathrm{n}}=2000 \mathrm{~g} \mathrm{~mol}^{-1}$ was kindly supplied by Bayer (Germany). Before being used, the PCD was heated at $90{ }^{\circ} \mathrm{C}$ in vacuo for $10 \mathrm{~h}$, while MDI (98\%) from SigmaAldrich (Germany) was used as received.

\section{Measurements}

Reduced viscosities ( $\eta_{\mathrm{red}} \mathrm{s}, \mathrm{dL} \mathrm{g} \mathrm{g}^{-1}$ ) of $0.5 \%$ polymer solution in 1,1,2,2-tetrachloroethane (TChE) were measured in an Ubbelohde viscometer (Poland) at $25^{\circ} \mathrm{C}$.

Attenuated total reflectance Fourier transform infrared (ATR-FTIR) spectra were obtained with a Bruker Tensor 27 FTIR spectrometer (Germany) using thin films. The FTIR spectra were recorded in the spectral range of $600-4000 \mathrm{~cm}^{-1}$ with 32 scans per spectrum with a resolution of $4 \mathrm{~cm}^{-1}$. Infrared carbonyl stretching region of the polymers was resolved into Gaussian curves using OPUS 7.2 software.

Thermogravimetry (TG) was carried out with a Netzsch STA 449 F1 Jupiter thermal analyzer (Germany) in the range of $40-1000{ }^{\circ} \mathrm{C}$ in helium (flow $=20 \mathrm{~cm}^{3} \mathrm{~min}^{-1}$ ), at the heating rate of $10{ }^{\circ} \mathrm{C} \mathrm{min}{ }^{-1}$. All $\mathrm{TG}$ measurements were taken in $\mathrm{Al}_{2} \mathrm{O}_{3}$ crucibles (mass of $160 \pm 1 \mathrm{mg}$ ). As a reference, empty $\mathrm{Al}_{2} \mathrm{O}_{3}$ crucible was applied. Sample masses of $10.2 \pm 0.1 \mathrm{mg}$ were used. The composition of the gas evolved during the decomposition process was analyzed by a Bruker Tensor 27 FTIR spectrometer (Germany) coupled online to a Netzsch STA instrument by Teflon transfer line with $2 \mathrm{~mm}$ diameter heated to $200{ }^{\circ} \mathrm{C}$. The FTIR spectra were recorded in the spectral range of $600-4000 \mathrm{~cm}^{-1}$ with 16 scans per spectrum at $4 \mathrm{~cm}^{-1}$ resolution.

Differential scanning calorimetry (DSC) curves were obtained with a Netzsch 204 calorimeter (Germany) in the range of -100 to $200{ }^{\circ} \mathrm{C}$. The reported transitions were taken from first and second heating scans. The scans were performed at the heating/cooling rate of $10{ }^{\circ} \mathrm{C} \mathrm{min}{ }^{-1}$ under nitrogen atmosphere (flow $=30 \mathrm{~cm}^{3} \mathrm{~min}^{-1}$ ). All DSC measurements were taken in aluminum pans with pierced lid (mass of $40 \pm 1 \mathrm{mg}$ ). As a reference, empty aluminum 
crucible was applied. Sample masses of $10.0 \pm 0.2 \mathrm{mg}$ were used. $T_{\mathrm{g}} \mathrm{s}$ for the polymer samples were taken as the inflection point on the curves of the heat-capacity changes. $T_{\mathrm{m}} \mathrm{s}$ were read at endothermic peak maxima. The linear base line was used to evaluate the heat of melting $(\Delta H)$.

Atomic force microscopy (AFM) was carried out on a Nanoscope V (VEECO, USA) microscope, in tapping mode in air. The phase data were recorded simultaneously. Silicon probes that were used (NSG30, NT-MDT, Russia) had a nominal spring constant of $20-100 \mathrm{~N} \mathrm{~m}^{-1}$. In order to compare the structure of all investigated samples, the imaging parameters were kept constant. Medium tapping technique was used to obtain phase images at $1 \mu \mathrm{m}$ scan size. The specimens used were the cuttings from crude polymers after 1 month.

$\mathrm{X}$-ray diffraction (XRD) measurements were taken using a PANalytical Empyrean apparatus (Holland) with a copper tube, nickel filter and focusing mirror. The XRD patterns of the investigated samples were obtained by measuring the number of impulses within a given angle over $4 \mathrm{~s}$. The measurements were taken every $0.01^{\circ}$. The XRD patterns were analyzed by the WAXSFIT computer program [20]. The program resolves a diffraction curve on diffraction peaks and an amorphous halo, which allows to estimate the degree of crystallinity. It was calculated as the ratio of the sum of crystalline to the total sum of crystalline and amorphous peaks areas. As crystalline peaks were assumed those whose full width at half-maximum (FWHM) was contained in the range of $0.5-1.8^{\circ}$.

The hardness of the polymers was measured by the Shore A/D method on a Zwick 7206/H04 hardness tester (Germany) at $23{ }^{\circ} \mathrm{C}$, and values were taken after $15 \mathrm{~s}$.

Tensile testing was performed on a Zwick/Roell Z010 (Germany) tensile testing machine according to Polish Standard PN-81/C-89034 (EN ISO Standard 527-1:1996 and 527-2:1996) at the speed of $100 \mathrm{~mm} \mathrm{~min}^{-1}$ at $23{ }^{\circ} \mathrm{C}$; tensile test pieces $1 \mathrm{~mm}$ thick and $6 \mathrm{~mm}$ wide (for the section measured) were cut from the pressed sheet.

Press molding was done with a Carver hydraulic press (USA) at $70-150{ }^{\circ} \mathrm{C}$ under $10-30 \mathrm{MPa}$ pressure.

The single lap shear strength of the polymers to copper plate, $100 \mathrm{~mm} \times 25 \mathrm{~mm} \times 1.5 \mathrm{~mm}$, was measured in accordance with Polish Standard PN-EN 1465:2009 by using a Zwick/Roell Z010 (Germany). The adhesive joint, $12.5 \mathrm{~mm} \times 25 \mathrm{~mm} \times 0.2 \mathrm{~mm}$, was prepared by pressing the polymer between the ends of two copper plates at $135-150{ }^{\circ} \mathrm{C}$ (prepared according to PN-EN-13887:2005) and then leaving them under a pressure of $30 \mathrm{MPa}$ to cool to room temperature. Next, the plates were fixed by tensile testing machine clips and underwent tensile testing, with the speed of $2 \mathrm{~mm} \mathrm{~min}^{-1}$ at $23{ }^{\circ} \mathrm{C}$.

Refractive index was measured at $23{ }^{\circ} \mathrm{C}$ by using Conbest Abbe's Refractometer Type 325 instrument
(Poland) according to method A of European Standard EN ISO 489:1999. 1-Bromonaphtalene was applied between the sample film and the prism shield.

The ultraviolet-visible (UV-Vis) spectra of the compression-molded 1-mm-thick sheets of the PCURs were determined by a UV-1800 (Shimadzu, Japan) UV spectrophotometer in the range of $300-900 \mathrm{~nm}$; sampling interval was $0.5 \mathrm{~nm}$.

\section{Polymer synthesis}

The PCURs, with the soft-segment content of 30,45 and $60 \mathrm{~mol} \%$, were prepared by a one-step melt polyaddition of the diol SE or ME, PCD and MDI at the $\mathrm{NCO} / \mathrm{OH}$ molar ratio of 1 .

The general procedure for the synthesis of the PCURs by this method was as follows. The diol SE or ME and PCD ( 0.01 mol together) were heated under dry nitrogen to $110^{\circ} \mathrm{C}$ in an oil bath. MDI $(0.01 \mathrm{~mol})$ was added to the melted and mixed dihydroxy compounds, and the mixing was continued until the viscosity increase made stirring impossible. The reaction temperature was gradually raised to $135{ }^{\circ} \mathrm{C}$, and the formed colorless rubber-like product was additionally heated at this temperature for $2 \mathrm{~h}$.

\section{Results and discussion}

The PCURs, obtained according to Scheme 1, were colorless, transparent or opaque materials. The $\eta_{\text {red }}$ values determined for these polymers, ranging from 1.15 to $1.61 \mathrm{dL} \mathrm{g}^{-1}$, pointed to their high molar masses. The polymers, with the exception of S-30, dissolved at room temperature in TChE, $N$-methyl-2-pyrrolidone, $N, N$ dimethylformamide and $N, N$-dimethylacetamide (DMAc), but they were partially soluble in tetrahydrofuran (THF) and insoluble in dimethyl sulfoxide (DMSO), both at room and elevated temperature. Polymer S-30 did not dissolve in DMSO, swelled in THF and DMAc and partially dissolved in the remaining solvents.

Table 1 gives designations, $\eta_{\text {red }}$ values and transmittance data for the PCURs.

The chemical structures of all the PCURs were confirmed by ATR-FTIR spectroscopy. The main absorption bands are given below, whereas representative spectra are shown in Fig. 1. Figure 1 also displays spectra obtained for the RPUR S and PCD. Additionally, the results of the deconvolution of the carbonyl stretching region for the RPURs and PCURs are given in Tables 2 and 3 and Figs. 2 and 3.

PCURs from diol SE $\left(\mathrm{cm}^{-1}\right)$ : 1531-1530 (N-H bending) and 3348-3338 (N-H stretching) of the urethane group; $1737-1702(\mathrm{C}=\mathrm{O}$ stretching $)$ of the urethane and 


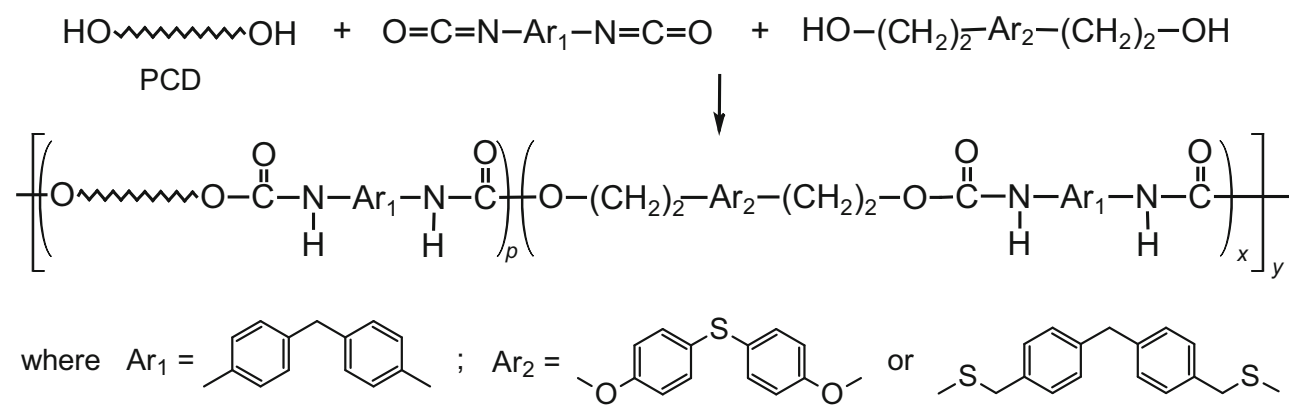

Scheme 1 Synthesis of PCURs

Table 1 Designations, $\eta_{\text {red }}$ values and transmittance data of the polymers

\begin{tabular}{|c|c|c|c|c|c|c|}
\hline \multirow[t]{2}{*}{ Polymer } & \multirow{2}{*}{$\begin{array}{l}\text { Chain } \\
\text { extender }\end{array}$} & \multirow{2}{*}{$\begin{array}{l}\text { Soft-segment } \\
\text { content } / \mathrm{mol} \%\end{array}$} & \multirow{2}{*}{$\begin{array}{l}\text { Hard-segment } \\
\text { content } / \text { mass } \%\end{array}$} & \multirow[t]{2}{*}{$\eta_{\text {red }} / \mathrm{dL} \mathrm{g}^{-1}$} & \multicolumn{2}{|c|}{ Transmittance/\% } \\
\hline & & & & & $T_{500}^{\mathrm{b}}$ & $T_{800}^{\mathrm{b}}$ \\
\hline S-30 & SE & 30 & 43.6 & $0.56^{\mathrm{a}}$ & 39.9 & 54.9 \\
\hline S-45 & & 45 & 31.8 & 1.61 & 39.5 & 54.3 \\
\hline S-60 & & 60 & 23.7 & 1.33 & - & - \\
\hline M-30 & $\mathrm{ME}$ & 30 & 45.1 & 1.15 & 61.8 & 73.6 \\
\hline M-45 & & 45 & 32.9 & 1.30 & $71.8(4.7)^{\mathrm{c}}$ & $79.4(14.9)^{\mathrm{c}}$ \\
\hline M-60 & & 60 & 24.5 & 1.42 & - & - \\
\hline
\end{tabular}

${ }^{\text {a }} \eta_{\text {red }}$ value of the soluble fraction

b Transmittance data at 500 and $800 \mathrm{~nm}$

c Transmittance data for a sample conditioned for 3 months at room temperature

carbonate groups; 1246-1243 (C-O stretching of the carbonate group and asymmetric $\mathrm{C}-\mathrm{O}-\mathrm{C}$ stretching in aliphatic-aromatic ether); 1065-1064 (symmetric C-O-C stretching) in aliphatic-aromatic ether; 791 (out-of-plane bending) of O-CO-O; 2939 and 2865-2862 (asymmetric and symmetric $\mathrm{C}-\mathrm{H}$ stretching) and 1465-1458 (asymmetric $\mathrm{C}-\mathrm{H}$ bending) of $\mathrm{CH}_{2} ; 1595-1593$ and 1492 (C-C stretching) of benzene ring; 819-818 (C-H bending) of $p$-disubstituted benzene ring.

PCURs from diol ME $\left(\mathrm{cm}^{-1}\right)$ : 1530-1528 (N-H bending) and 3346-3342 (N-H stretching) of the urethane group; 1736-1710 $(\mathrm{C}=\mathrm{O}$ stretching $)$ of the urethane and carbonate groups; 1248-1246 (C-O stretching) of the carbonate group; 791 (out-of-plane bending) of OCO-O; 2939-2938 and 2865-2860 (asymmetric and symmetric C-H stretching) and 1467-1466 (asymmetric C-H bending) of $\mathrm{CH}_{2}$; 1597-1596 (C-C stretching) of benzene ring; 816-815 ( $\mathrm{C}-\mathrm{H}$ bending) of $p$-disubstituted benzene ring.

The deconvolution of the carbonyl stretching region for the RPURs revealed that this band is composed from four (for S) or five (for M) peaks. The peaks at 1730 and $1729 \mathrm{~cm}^{-1}$ can be attributed to the non-H-bonded carbonyl groups, while those at $1702-1686$ and $1678-1656 \mathrm{~cm}^{-1}$ can be assigned to H-bonded carbonyl groups. Taking into account the areas of peaks corresponding to $\mathrm{H}$-bonded carbonyl groups and small degrees of crystallinity of these polymers (see XRD study), peaks at $1702-1686 \mathrm{~cm}^{-1}$ should be ascribed to the amorphous phase and those at $1678-1656 \mathrm{~cm}^{-1}$ to crystalline phase. Similar results are to be found in subject literature [21].

In the PCURs, carbonyl stretching region was composed of four peaks. Considering non-H-bonded carbonyl band in RPURs (1730 and $1729 \mathrm{~cm}^{-1}$ ) and carbonyl band in PCD $\left(1732 \mathrm{~cm}^{-1}\right)$, peaks at $1738-1735 \mathrm{~cm}^{-1}$ can be attributed to the "free" carbonyl from carbonate and urethane groups. The peaks at $1721-1719 \mathrm{~cm}^{-1}$, which were absent for RPURs, should be assigned to H-bonded carbonyl from carbonate groups. The other peaks at 1710-1686 $\mathrm{cm}^{-1}$ correspond to $\mathrm{H}$-bonded urethane carbonyls in low-ordered (1696-1686 $\mathrm{cm}^{-1}$ ) or completely amorphous (1710$1703 \mathrm{~cm}^{-1}$ ) hard-segment phase, with the area of the former being visibly smaller. There are no observed peaks relating to $\mathrm{H}$-bonded carbonyl groups in crystalline hardsegment phase.

In both series of the PCURs, an increase in the soft-segment content caused an increase in the fraction of non-Hbonded "free" carbonate and urethane carbonyl groups and a 
Fig. 1 FTIR spectra of the PCURs containing $45 \mathrm{~mol} \%$ PCD as well as RPUR $S$ and PCD

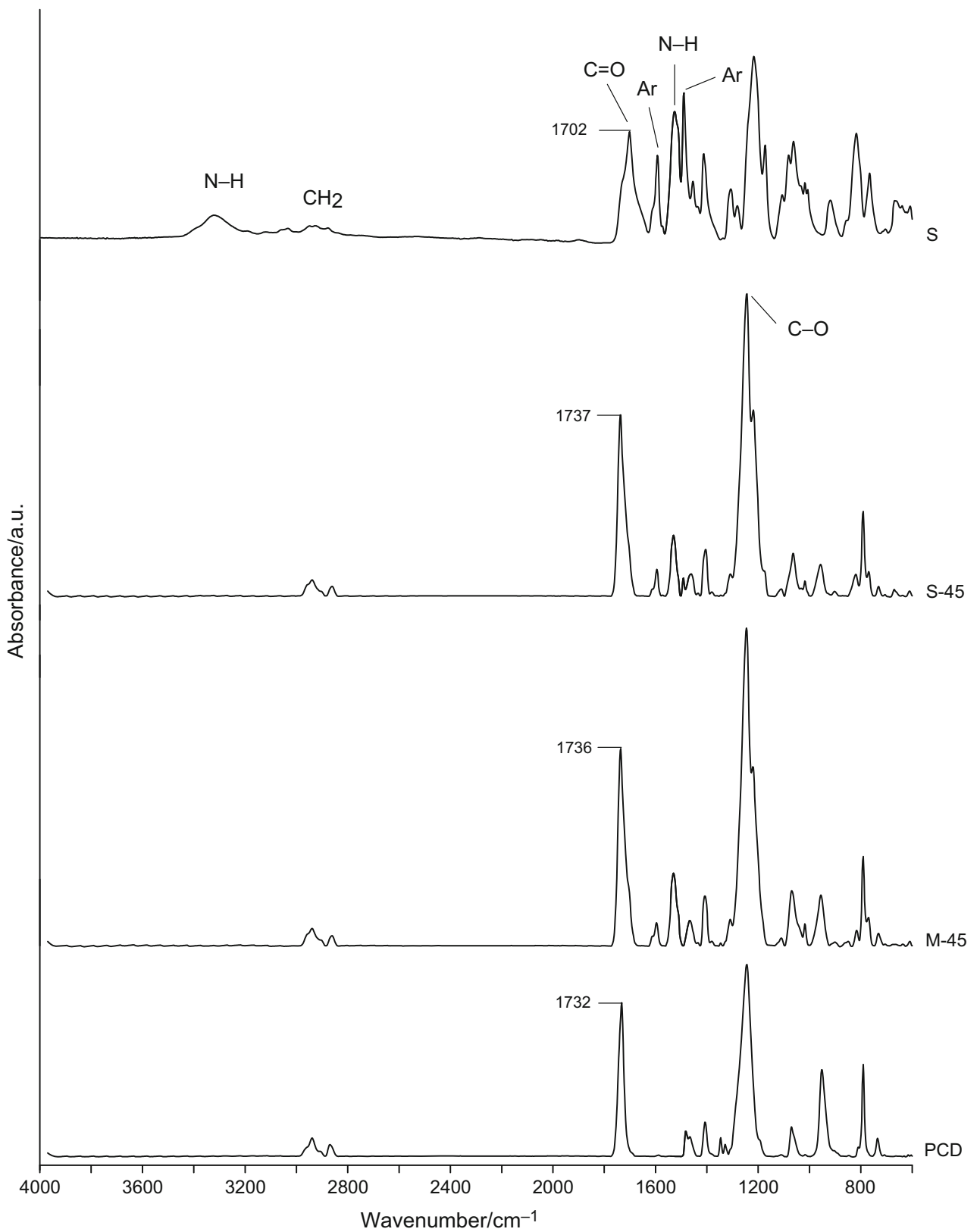

Table 2 Characteristics of the H-bonded and non-H-bonded carbonyl bands for the RPURs

\begin{tabular}{|c|c|c|c|c|c|c|c|c|c|c|}
\hline \multirow[t]{2}{*}{ RPUR } & \multicolumn{4}{|c|}{$\mathrm{H}$-bonded urethane $\mathrm{C}=\mathrm{O}$ band in crystalline phase } & \multicolumn{4}{|c|}{$\mathrm{H}$-bonded urethane $\mathrm{C}=\mathrm{O}$ band in amorphous phase } & \multicolumn{2}{|c|}{$\begin{array}{l}\text { Non-H-bonded urethane } \\
\mathrm{C}=\mathrm{O} \text { band }\end{array}$} \\
\hline & $v / \mathrm{cm}^{-1}$ & Area/\% & $v / \mathrm{cm}^{-1}$ & Area/\% & $v / \mathrm{cm}^{-1}$ & Area/\% & $v / \mathrm{cm}^{-1}$ & Area/\% & $v / \mathrm{cm}^{-1}$ & Area/\% \\
\hline S & 1656 & 8.5 & 1675 & 8.8 & & & 1701 & 55.4 & 1730 & 27.3 \\
\hline M & 1665 & 6.4 & 1678 & 4.9 & 1686 & 1.6 & 1702 & 60.8 & 1729 & 26.3 \\
\hline
\end{tabular}

decrease in the fraction of H-bonded urethane carbonyl groups. At the same time, a decrease in the fraction of $\mathrm{H}$-bonded carbonate carbonyl groups existed. This points to the decrease in the degree of phase mixing between the hard and soft segments, confirmed by further DSC data.

\section{DSC}

The numerical data obtained $\left(T_{\mathrm{g}}, T_{\mathrm{m}}\right.$ and $\Delta H$ values) after one-month conditioning for all the PCURs are summarized in Table 4, while the DSC curves are presented in 
Table 3 Characteristics of the H-bonded and non-H-bonded carbonyl bands for the PCURs

\begin{tabular}{|c|c|c|c|c|c|c|c|c|}
\hline \multirow[t]{2}{*}{ PCUR } & \multicolumn{4}{|c|}{$\begin{array}{l}\mathrm{H} \text {-bonded urethane } \mathrm{C}=\mathrm{O} \\
\text { band in amorphous phase }\end{array}$} & \multicolumn{2}{|c|}{$\begin{array}{l}\text { H-bonded carbonate } \\
\mathrm{C}=\mathrm{O} \text { band }\end{array}$} & \multicolumn{2}{|c|}{$\begin{array}{l}\text { Non- } \mathrm{H} \text {-bonded carbonate } \\
\text { and urethane } \mathrm{C}=\mathrm{O} \text { band }\end{array}$} \\
\hline & $v / \mathrm{cm}^{-1}$ & Area/\% & $v / \mathrm{cm}^{-1}$ & Area/\% & $v / \mathrm{cm}^{-1}$ & Area/\% & $\mathrm{v} / \mathrm{cm}^{-1}$ & Area/\% \\
\hline S-30 & 1686 & 1.4 & 1703 & 22.0 & 1719 & 10.9 & 1738 & 65.7 \\
\hline S-45 & 1689 & 1.0 & 1708 & 20.0 & 1720 & 7.1 & 1737 & 71.9 \\
\hline S-60 & 1696 & 3.5 & 1710 & 12.3 & 1720 & 2.9 & 1735 & 81.3 \\
\hline M-30 & 1690 & 3.1 & 1709 & 23.4 & 1721 & 12.4 & 1737 & 61.1 \\
\hline M-45 & 1687 & 1.0 & 1707 & 19.8 & 1720 & 6.4 & 1737 & 72.8 \\
\hline M-60 & 1696 & 3.4 & 1710 & 12.3 & 1719 & 1.8 & 1735 & 82.5 \\
\hline
\end{tabular}
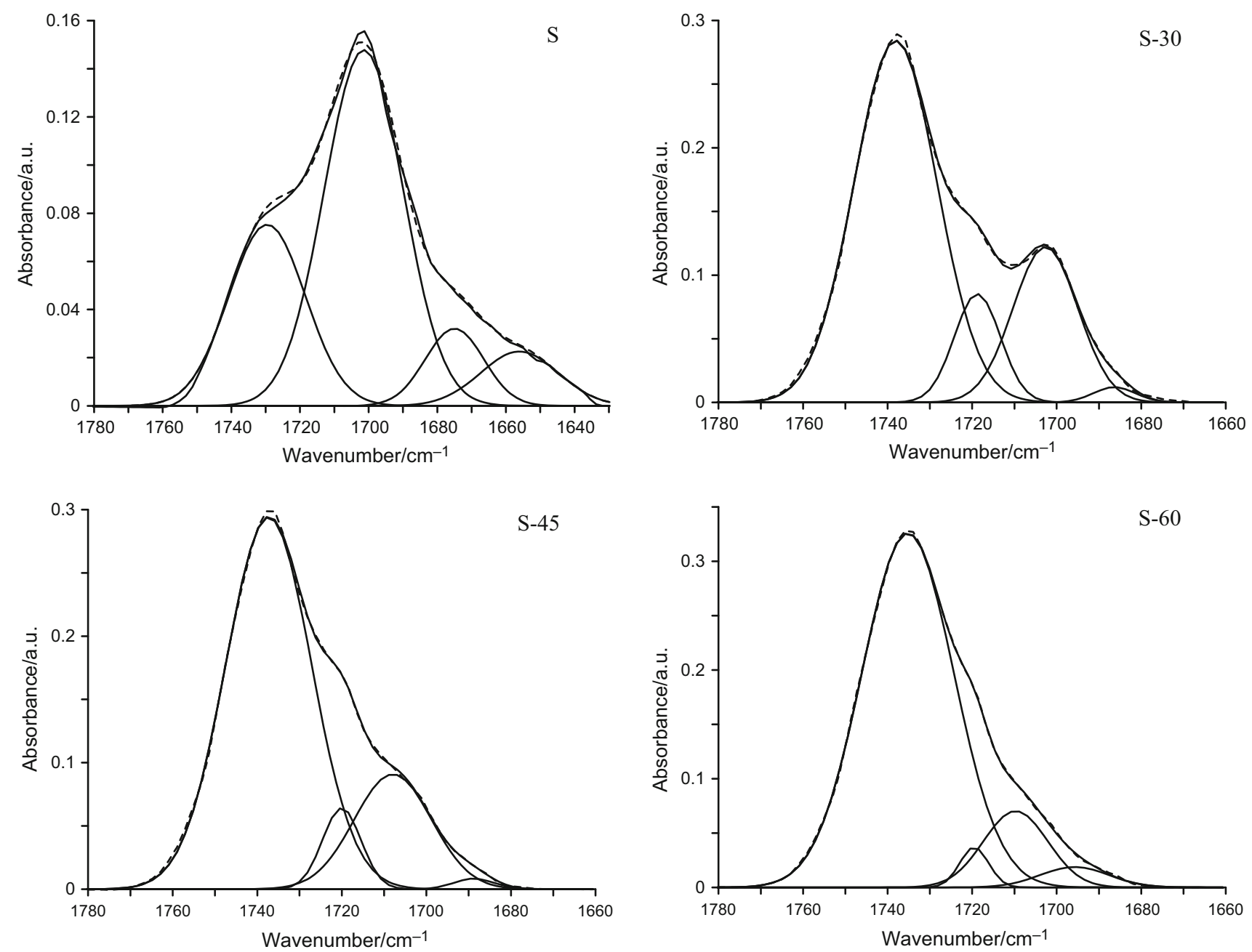

Fig. 2 Deconvolution of the carbonyl stretching region of the polymers based on diol SE (dashed line recorded spectra, solid line resolved peaks)

Figs. 4 and 5. For the purpose of comparison, Table 4 and Figs. 4 and 5 also contain data received for the RPURs and PCD.

The DSC curves of all the PCURs based on diol SE from the first heating scans displayed glass transition of the soft segment in the range of -7 to $20{ }^{\circ} \mathrm{C}$ and from one to three endothermic peaks with maxima in the range of $44-159{ }^{\circ} \mathrm{C}$. Comparing the data obtained for PCD (pure soft segment) and RPUR S (model of the diol SE-based hard segment) (see Table 4) and PCURs, it can be seen that endothermic 

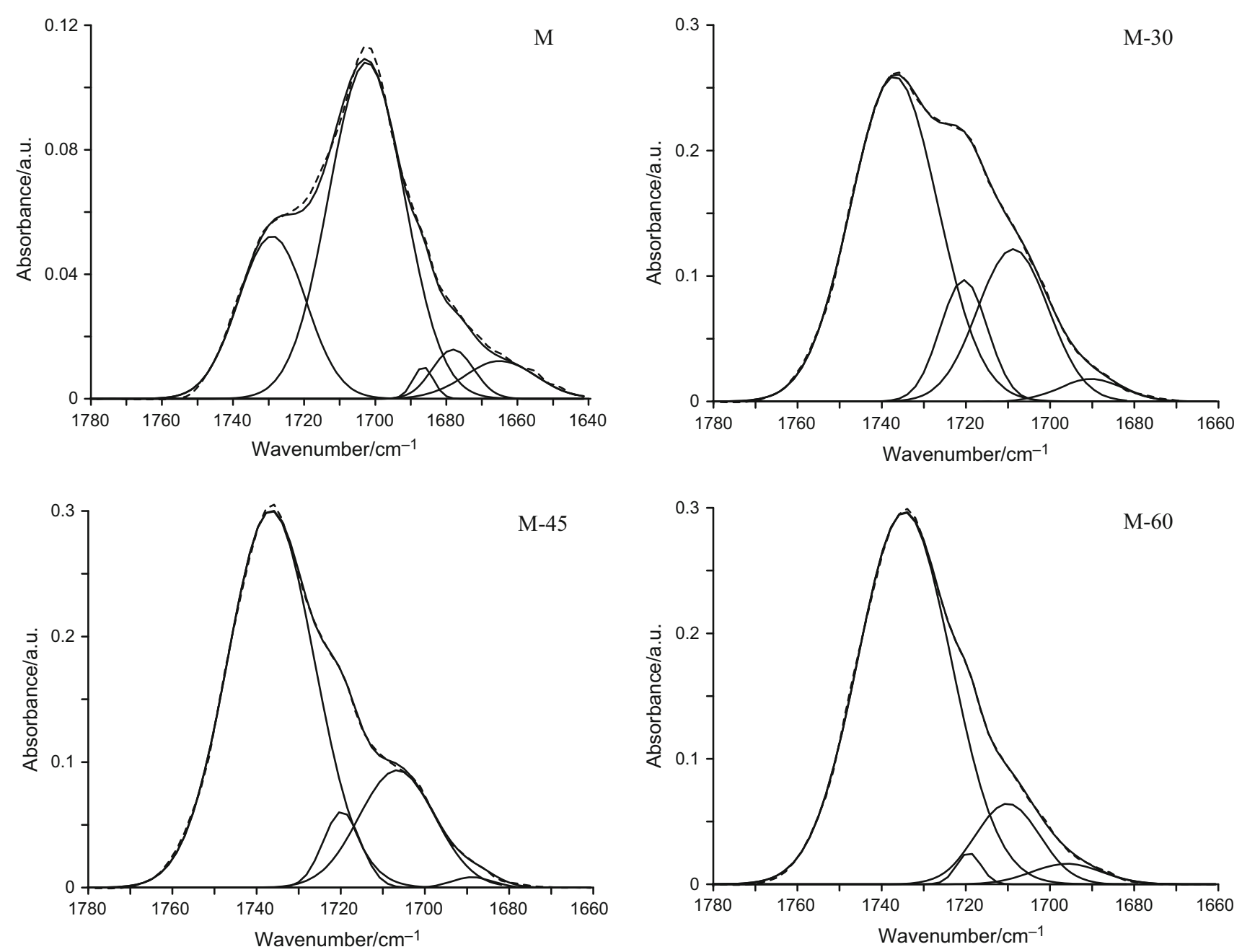

Fig. 3 Deconvolution of the carbonyl stretching region of the polymers based on diol ME (dashed line recorded spectra, solid line resolved peaks)

Table 4 DSC data of the polymers

\begin{tabular}{|c|c|c|c|c|c|c|}
\hline \multirow[t]{2}{*}{ Polymer } & \multicolumn{2}{|c|}{$T_{\mathrm{g}} /{ }^{\circ} \mathrm{C}$} & \multicolumn{2}{|l|}{$T_{\mathrm{m}} /{ }^{\circ} \mathrm{C}$} & \multicolumn{2}{|l|}{$\Delta H / \mathrm{J} \mathrm{g}^{-1}$} \\
\hline & $\mathrm{I}^{\mathrm{a}}$ & $\mathrm{II}^{\mathrm{a}}$ & $\mathrm{I}^{\mathrm{a}}$ & $\mathrm{II}^{\mathrm{a}}$ & $\mathrm{I}^{\mathrm{a}}$ & $\mathrm{II}^{\mathrm{a}}$ \\
\hline $\mathrm{S}$ & & 89 & $105 ; 159,168$ & & $1.0 ; 32.1$ & \\
\hline$S-30$ & 20 & 18 & $45 ; 146,159$ & & $0.4 ; 1.4$ & \\
\hline S-45 & -7 & 2 & $44 ; 101$ & & $0.9 ; 4.1$ & \\
\hline$S-60$ & -2 & -14 & 44 & & 23.4 & \\
\hline M & 70 & 72 & 130,153 & & 37.0 & \\
\hline M-30 & -8 & 8 & 151,156 & & 11.6 & \\
\hline M-45 & -8 & -8 & 38 & & 0.2 & \\
\hline M-60 & -9 & -14 & 40 & & 17.5 & \\
\hline PCD & -42 & -57 & 21,56 & 6,$30 ; 53$ & 89.3 & $17.5 ; 56.8$ \\
\hline
\end{tabular}

${ }^{\text {a }}$ I and II, first and second heating scans, respectively

peaks with maximum at $\sim 44{ }^{\circ} \mathrm{C}$ are associated with the melting of soft-segment domains, while those at higher temperatures $\left(101-159{ }^{\circ} \mathrm{C}\right)$ are connected with the melting of hard-segment domains. In the case of polymers S-30 and $\mathrm{S}-45$, small $\Delta H$ values of these lower- and higher-temperature endothermic transitions pointed to a very small degree 


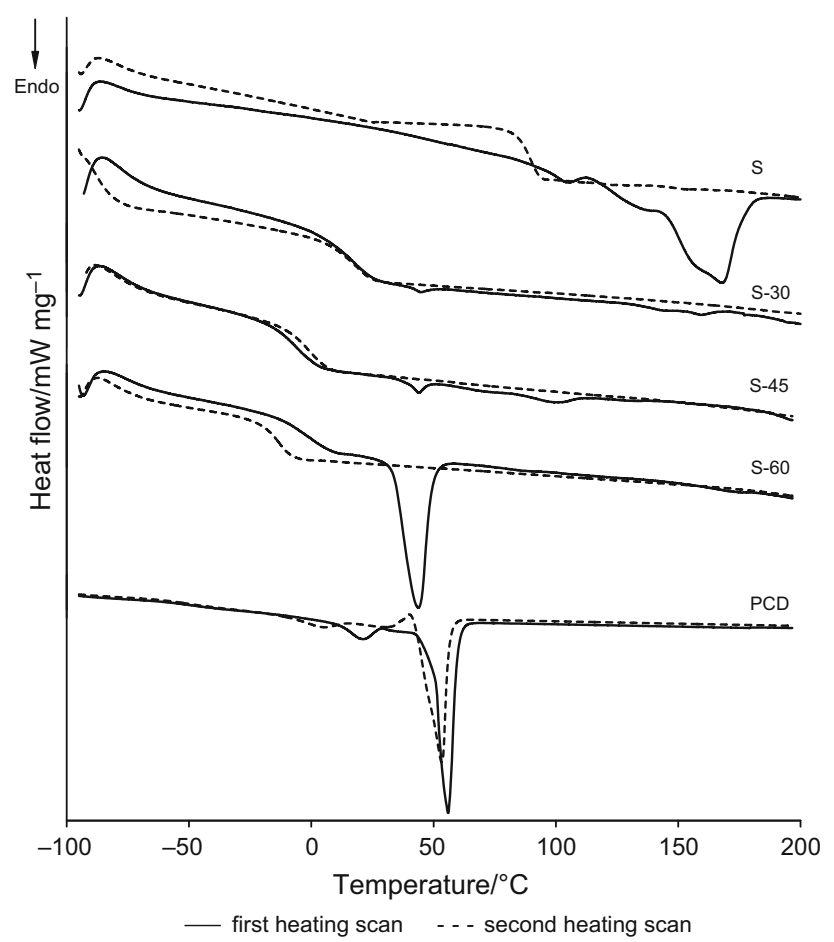

Fig. 4 DSC curves of the diol SE-based polymers: RPUR S and PCURs after one-month conditioning as well as PCD

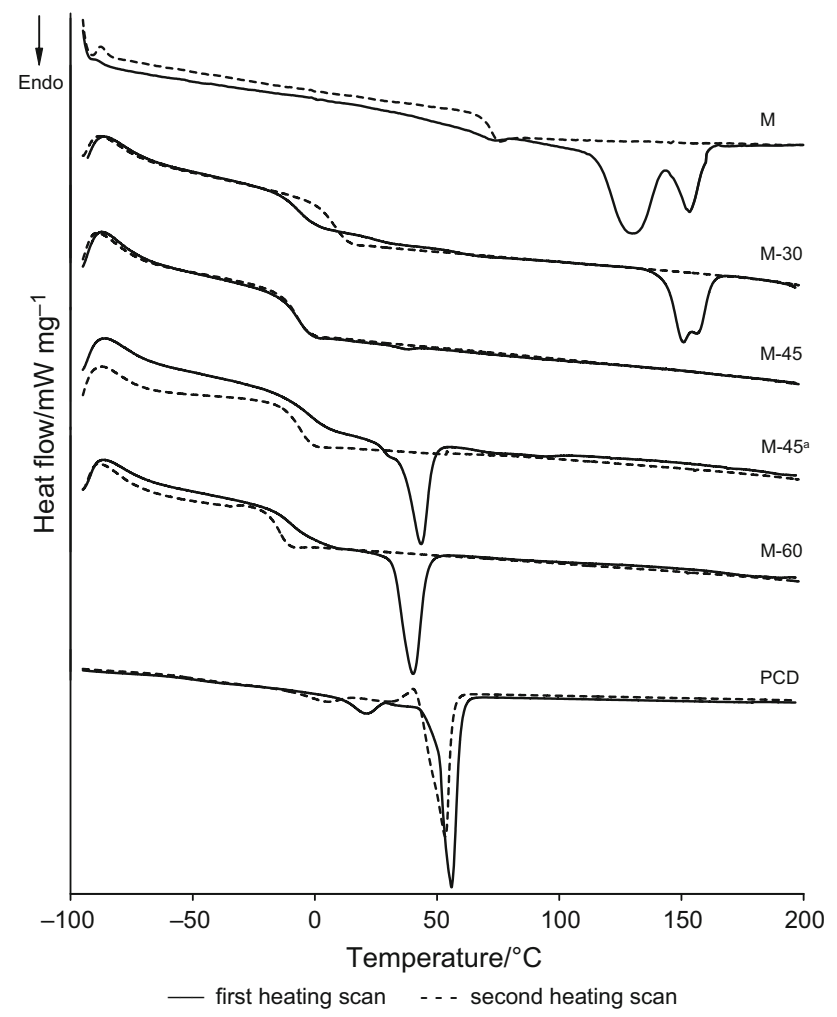

Fig. 5 DSC curves of the diol ME-based polymers: RPUR $M$ and PCURs after one-month conditioning (M-30, M-45 and M-60) and additionally after a 3-month conditioning $\left(\mathrm{M}-45^{\mathrm{a}}\right)$ as well as PCD of ordering of these polymers, both in soft-segment and hard-segment domains. Polymer with the highest soft-segment content (S-60) was characterized by a much higher degree of ordering in soft-segment domains and lack of ordering in hard-segment domains (the presence only of the sharp and high peak at $44^{\circ} \mathrm{C}$ ). On the DSC curves from the second heating scans merely glass transition, ranging from -14 to $18{ }^{\circ} \mathrm{C}$, and shifting to lower temperatures together with the increase in soft-segment content, was observed. Higher $T_{\mathrm{g}}$ recorded in the first heating scan for polymer S-60 may be the result of the existence of a crystalline phase within soft-segment domains.

The DSC curves of the PCURs based on diol ME from the first heating scans showed almost the same glass transition of the soft segment ( -9 to $-8{ }^{\circ} \mathrm{C}$ ) and two overlapping endothermic peaks with maxima at $151-156^{\circ} \mathrm{C}$ (for M-30), connected with the melting of hard-segment domains or one endothermic peak with maximum at $\sim 39{ }^{\circ} \mathrm{C}$ (for M-45 and M-60), corresponding to the melting of soft-segment domains. On the basis of the $\Delta H$ values, it can be seen that polymer M-45 is amorphous, while polymers M-30 and M-60 possess relatively wellordered structures. The DSC curves from the second heating scans, in the same way as in the case of the PCURs obtained from diol SE, showed only glass transition. Established $T_{\mathrm{g}}$ values, in the range of -14 to $8{ }^{\circ} \mathrm{C}$, lowered as the soft-segment content grew.

On the whole, lower $T_{\mathrm{g}}$, both from the first and second heating scans, were exhibited by the PCURs based on diol ME, especially that containing $30 \mathrm{~mol} \%$ PCD. All the synthesized polymers, with the exception of S-30, showed $T_{\mathrm{g}}$ below room temperature, typical of elastomers. Accepting as a criterion microphase separation, the difference between $T_{\mathrm{g}}$ values of pure PCD soft segments and the PCURs, it can be said that the polymers of $\mathrm{M}$ series showed a higher degree of microphase separation than the analogous ones of S series. It needs to be stressed that these newly obtained polymers when considered with their analogs based on BD showed higher or similar degree of microphase separation [22, 23].

In order to determine the tendency of PCD soft segment to crystallize (cold harden) during storage, DSC studies were additionally carried out after a three-month conditioning of the PCURs at room temperature. There were no significant differences in the course of the obtained DSC curves. In the case only of polymer M-45 on the DSC curve from the first heating scan appeared endothermic peak at $44{ }^{\circ} \mathrm{C}$ connected with the melting of the soft segment $\left(\Delta H 12.0 \mathrm{~J} \mathrm{~g}^{-1}\right)$ and $T_{\mathrm{g}}$ slightly increased (from -8 to $-1{ }^{\circ} \mathrm{C}$ ). The DSC curves obtained for this polymer are presented in Fig. 5.

It is obvious that the spontaneous crystallization of the soft segment, observed for samples S-60, M-60 and M-45, is accompanied by a loss in elastic properties of the polymers as well as diminished transparency. 

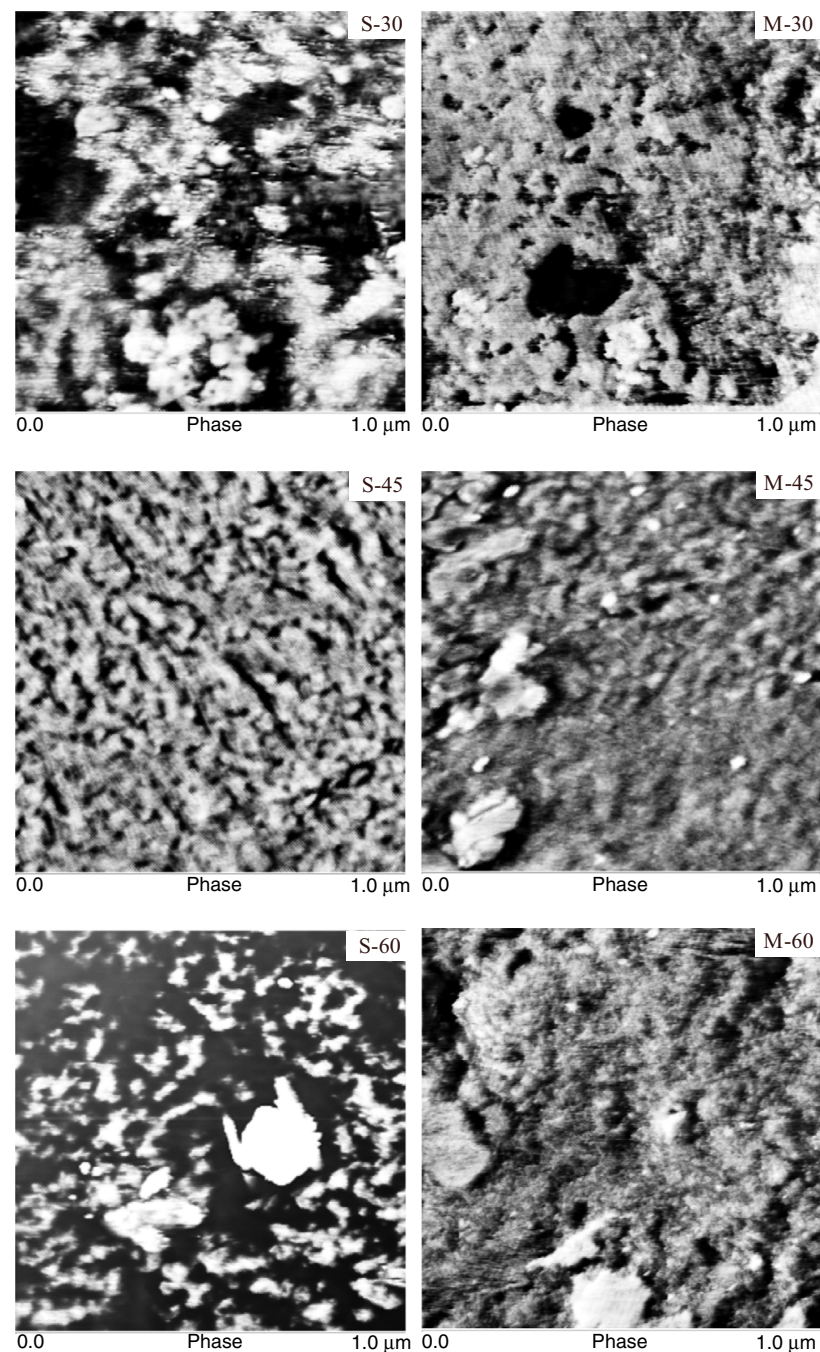

Fig. 6 AFM phase images of the PCURs

\section{Transparency}

Examination related to the PCURs with 30 and $45 \mathrm{~mol} \%$ soft-segment content directly after synthesis or after onemonth conditioning at room temperature was not opaque. In the case of polymer M-45, which with the passing of time was losing its transparency, the measurement was taken also after 3 months. The obtained numerical data are presented in Table 1. It follows from them that the transparency of these materials depended more on crystallization of soft segments than of hard segments. Nontransparent were polymers S-60 and M-60. Polymer M-45 at first showed a good transparency (transmittance at $500 \mathrm{~nm}: 71.8 \%$, at $800 \mathrm{~nm}$ : $79.4 \%$ ), but after 3 months following the crystallization of PCD, it became opaque. Among the remaining polymers, a relatively good transparency (transmittance at $500 \mathrm{~nm}$ : $61.8 \%$, at $800 \mathrm{~nm}: 73.6 \%$ ) exhibited polymer M-30, whose DSC curve did not indicate any ordering of the soft segment.
AFM

A heterogeneous bulk morphology of the examined PCURs was confirmed by the phase AFM images (with $1 \mu \mathrm{m}$ scan size) obtained after a monthly conditioning at room temperature, which is shown in Fig. 6. The dark matrix of lower modulus corresponds to the soft-segment-rich domains, and the brighter dispersed domains of higher modulus correspond to the hard segments. Smaller differences in the appearance of the phase images can be seen for the polymers based on diol ME, characterized by similar $T_{\mathrm{g}}$ values. Moreover, in this series less distinct phase contrast was observed in comparison with that of diol SE series, the explanation being in the smaller difference of the hardness between soft- and hard-segment-rich domains. The AFM images of polymers based on diol SE show bright aggregates with a circular structure, while those of the ones based on diol ME, apart from less numerous aggregates, also demonstrate areas with randomly oriented rod-like features, especially visible for M-60.

\section{TG}

The decomposition process of all the synthesized PCURs was performed in inert atmosphere. Moreover, for the polymers with 30 mol\% PCD content (S-30 and M-30) an analysis of volatile decomposition products was performed by the TG coupled with FTIR spectroscopy (TG-FTIR). The TG and DTG data obtained are given in Table 5 and Figs. 7 and 8, while the FTIR spectra of decomposition volatile products of polymers are presented in Fig. 9. For the purpose of comparison, Table 5 gives numerical data received for the RPURs examined earlier [12, 17] as well as PCD.

The PCURs from diol ME showed somewhat higher $T_{1}$ than the analogous ones from diol SE and independent of soft-segment content (290-292 vs. $284-290{ }^{\circ} \mathrm{C}$ ). In the case of the $\mathrm{S}$ series PCURs, one can notice the mutual stabilization effect of hard and soft segments [24]; this temperature increased with the rise of PCD content and was higher than that of RPUR $S\left(280^{\circ} \mathrm{C}\right)$ and PCD (227 $\left.{ }^{\circ} \mathrm{C}\right) . T_{5}$ and $T_{10}$ also increased as PCD content grew, but for S-30 were lower than those for RPUR S. In the M series PCURs stabilization effect was not seen; not only $T_{1}$ but also $T_{5}$ and $T_{10}$ were lower than for RPUR M although they were higher than those received for PCD. In both series, however, $T_{50}$ values for PCURs were lower than for RPURs and came closer to the value for PCD.

All the obtained PCURs based on diol SE decomposed in three stages. The DTG curves showed two relatively sharp peaks with maxima at 348-356 and $398-408{ }^{\circ} \mathrm{C}$, and a small intense and broad peak visible as a shoulder with the accepted maximum at $450{ }^{\circ} \mathrm{C}$. The first peak 
showing the highest intensity may relate to the decomposition of the urethane and carbonate linkages. The second peak, of clearly lesser intensity (diminishing with the increase in PCD content), as well as the shoulder, can be mainly ascribed to the further decomposition of the hard segments. It should be noted that the decomposition of isolated hard segment (RPUR S) above temperature about $390{ }^{\circ} \mathrm{C}$ [17] took a different course from that built into the structure of PCURs. In this area, DTG curve of this polymer exhibited only a small shoulder. Similar trend could be observed in analogous PCURs based on PHCD of $M_{\mathrm{n}}=860 \mathrm{~g} \mathrm{~mol}^{-1}$ [18].

In the case of the polymers derived from diol ME, no distinct differences in the course of DTG curves were to be seen. Both PCURs and RPUR M decomposed in two stages. There was one large intense peak visible with maximum at $346-348{ }^{\circ} \mathrm{C}$ for PCURs and $373{ }^{\circ} \mathrm{C}$ for RPUR $\mathrm{M}$, and a small intense and broad peak with maximum at $435{ }^{\circ} \mathrm{C}$ for PCURs and $521{ }^{\circ} \mathrm{C}$ for RPUR M. Thus, the main decomposition of all these polymers occurred at the first stage, and in the case of PCURs, main decomposition of the hard segments took place together with decomposition of the soft segments.

In order to interpret these differences in the course of the decomposition of the discussed polymers, TG-FTIR analysis was performed.

FTIR spectrum recorded during the first decomposition stage ( $T_{\max }$ at $348{ }^{\circ} \mathrm{C}$ ) for PCUR S-30 (see Fig. 9) exhibits absorption bands typical of carbon dioxide, at $2359-2310 \mathrm{~cm}^{-1}$ (very strong), attributed to asymmetric stretching vibration, at $669 \mathrm{~cm}^{-1}$, associated with the degenerate bending vibration, and at $\sim 3800-3600 \mathrm{~cm}^{-1}$ corresponding to combination bands. In the spectrum, there are also visible bands at 2937 and $2878 \mathrm{~cm}^{-1}$, characteristic of asymmetric and symmetric $\mathrm{C}-\mathrm{H}$ stretching

Table 5 TG data of the polymers

\begin{tabular}{llllll}
\hline Polymer & $T_{1}^{\mathrm{a}} /{ }^{\circ} \mathrm{C}$ & $T_{5}^{\mathrm{b}} /{ }^{\circ} \mathrm{C}$ & $T_{10}^{\mathrm{c}} /{ }^{\circ} \mathrm{C}$ & $T_{50}^{\mathrm{d}} /{ }^{\circ} \mathrm{C}$ & $T_{\max }^{\mathrm{e}} /{ }^{\circ} \mathrm{C}$ \\
\hline S & 280 & 310 & 324 & 365 & 370,405 \\
S-30 & 284 & 308 & 319 & 356 & $348,398,450$ \\
S-45 & 287 & 311 & 323 & 356 & $351,403,450$ \\
S-60 & 290 & 313 & 324 & 356 & $356,408,450$ \\
M & 295 & 333 & 344 & 380 & 373,521 \\
M-30 & 292 & 313 & 322 & 348 & 346,435 \\
M-45 & 290 & 312 & 322 & 350 & 348,435 \\
M-60 & 292 & 309 & 319 & 349 & 347,435 \\
PCD & 227 & 282 & 309 & 354 & 363 \\
\hline
\end{tabular}

a,b,c,d The temperature of 1, 5, 10 and $50 \%$ mass loss from the TG curve, respectively

e The temperature of the maximum rate of mass loss from the DTG curve

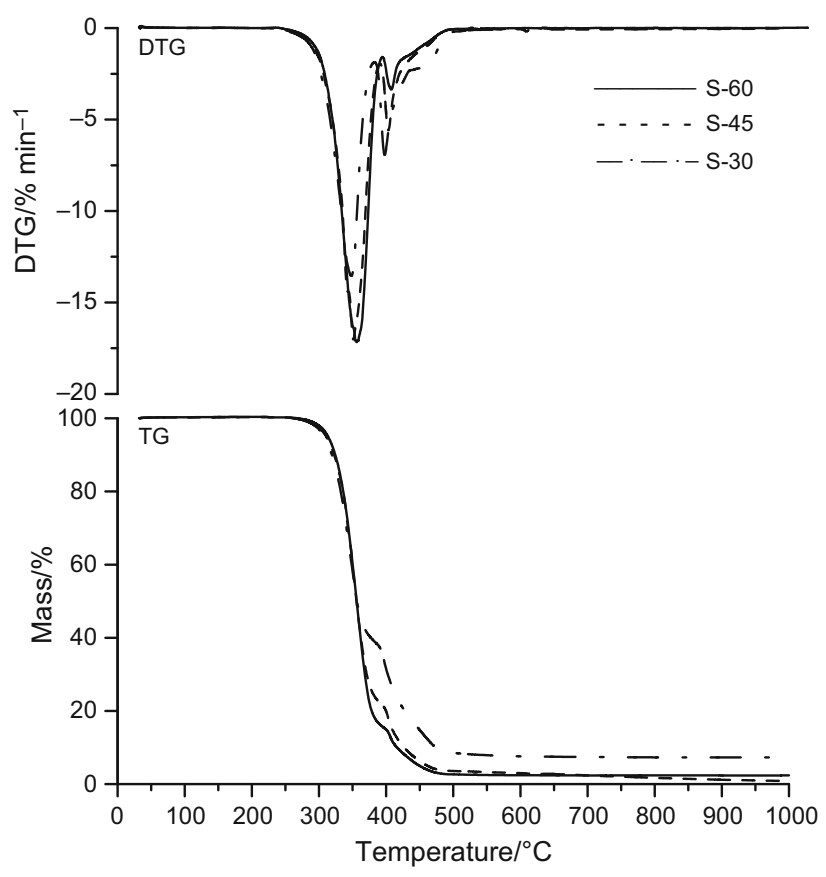

Fig. 7 DTG and TG curves of PCURs based on diol SE

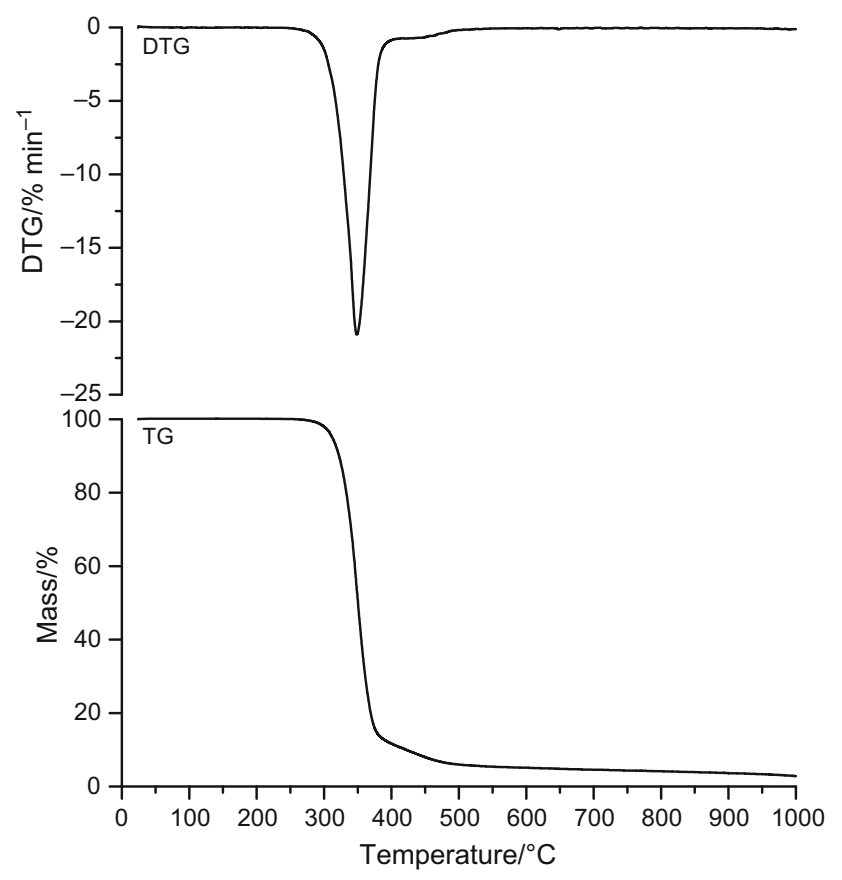

Fig. 8 DTG and TG curves of PCUR M-30

vibration, and at 1454 and $1388 \mathrm{~cm}^{-1}$, characteristic of asymmetric and symmetric $\mathrm{C}-\mathrm{H}$ bending vibration, of methylene and methyl groups. A band at $3083 \mathrm{~cm}^{-1}$, connected with $\mathrm{C}-\mathrm{H}$ stretching vibration, indicates the existence of unsaturated compounds, whereas bands at 999 and $917 \mathrm{~cm}^{-1}$, associated with $\mathrm{C}-\mathrm{H}$ out-of-plane deformation vibration, and at $1640 \mathrm{~cm}^{-1}$, associated with $\mathrm{C}=\mathrm{C}$ 
Fig. 9 FTIR spectra of volatile products obtained at the maximum rate of mass loss of the thermal decomposition of PCURs S-30 (for the first, second and third stages) and M-30 (for the first and second stages)

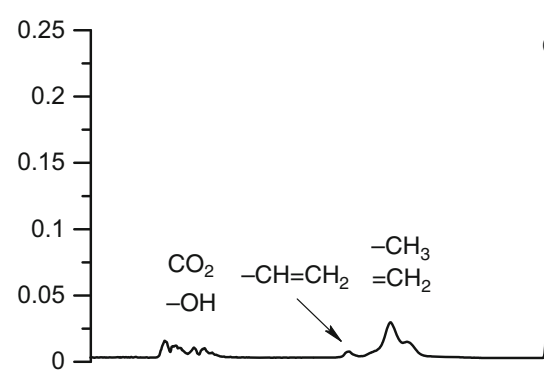

$\mathrm{CO}_{2}$
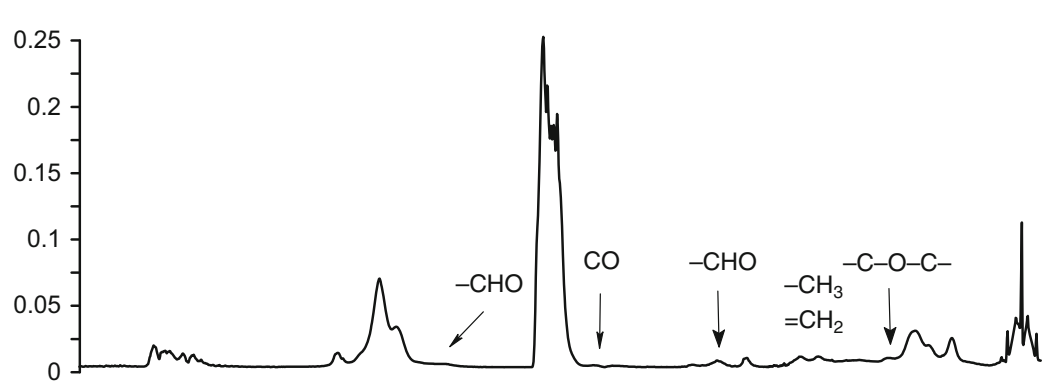

S-30 $\left(348^{\circ} \mathrm{C}\right)$
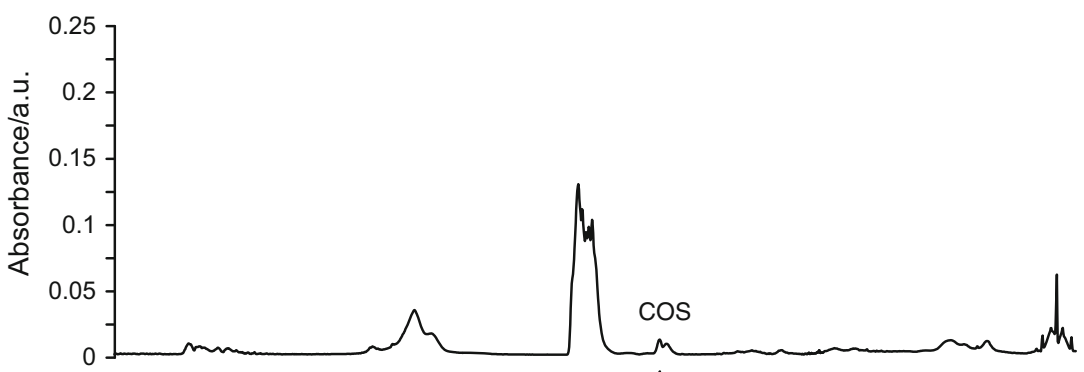

$\mathrm{S}-30\left(450^{\circ} \mathrm{C}\right)$
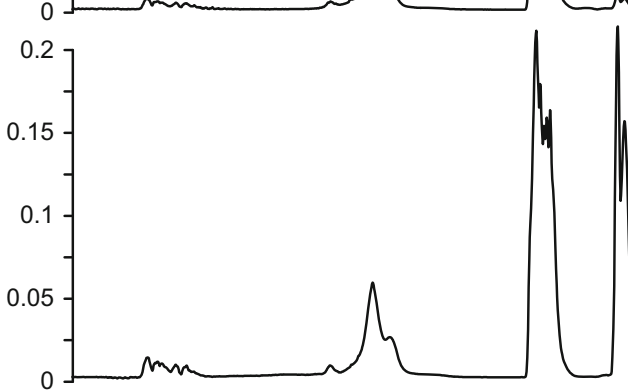

S-30 $\left(398^{\circ} \mathrm{C}\right)$

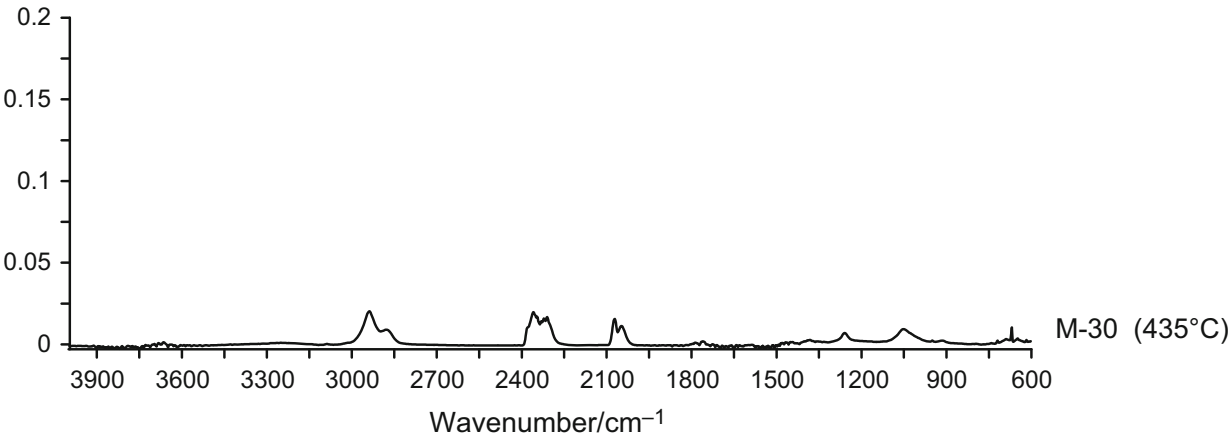

stretching vibration, suggest that those are also vinyl compounds. The forming of primary alcohols confirms the presence of a band at $1046 \mathrm{~cm}^{-1}$, associated with $\mathrm{C}-\mathrm{O}$ stretching vibration, and at $3633-3600 \mathrm{~cm}^{-1}$, associated with $\mathrm{O}-\mathrm{H}$ stretching vibration.
In the spectrum from the second decomposition stage ( $T_{\max }$ at $398^{\circ} \mathrm{C}$ ), moreover, appeared bands, indicating the existence of aliphatic ethers (at $1136 \mathrm{~cm}^{-1}$, connected with C-O stretching vibration), aldehydes (at $\sim 2700 \mathrm{~cm}^{-1}$, associated with $\mathrm{C}-\mathrm{H}$ stretching vibration, 


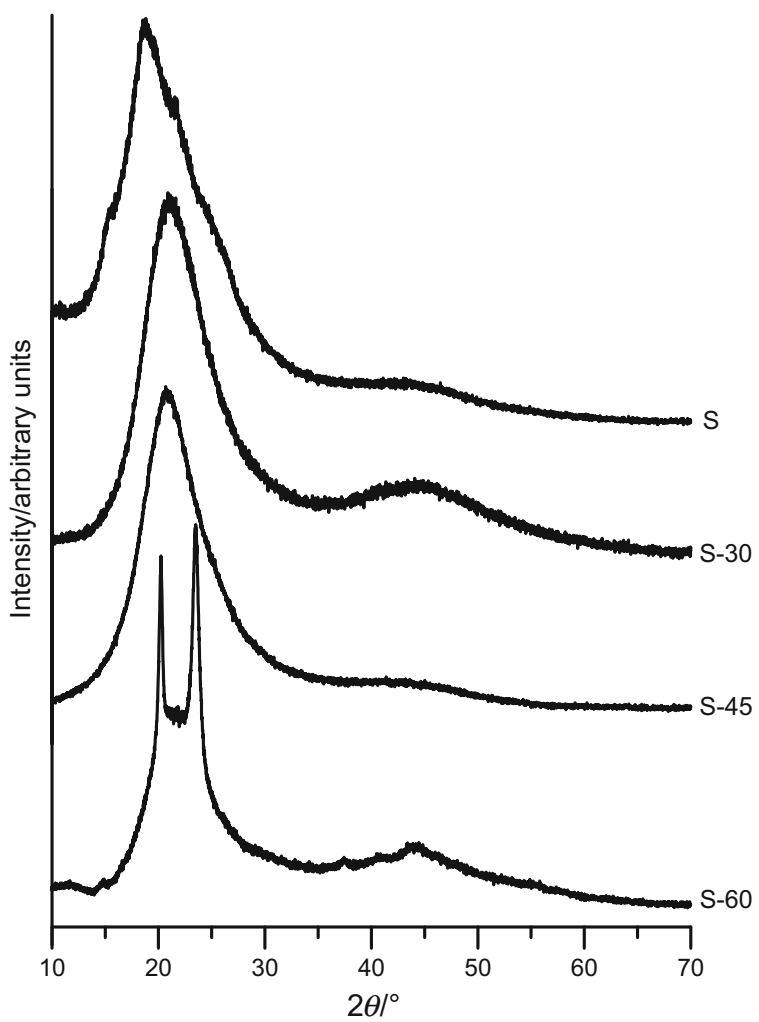

Fig. 10 XRD patterns of the polymers based on diol SE: RPUR S and PCURs after one-month conditioning

and at $1745 \mathrm{~cm}^{-1}$, with $\mathrm{C}=\mathrm{O}$ stretching vibration of aldehyde group) and carbon monoxide (at $2184 \mathrm{~cm}^{-1}$, attributed to stretching vibration). In turn, spectrum from the third stage $\left(T_{\max }\right.$ at $\left.450{ }^{\circ} \mathrm{C}\right)$ additionally revealed bands typical of carbonyl sulfide (at 2072 and $2047 \mathrm{~cm}^{-1}$, characteristic of asymmetric and symmetric $\mathrm{C}=\mathrm{O}$ stretching vibration [25-27]).

An intensive evolution of carbon dioxide should be ascribed to a decomposition of carbonate linkages of soft segments and urethane linkages independent of the manner of their decomposition [24, 28, 29]. As no amine compounds were detected at any stage, we may assume that

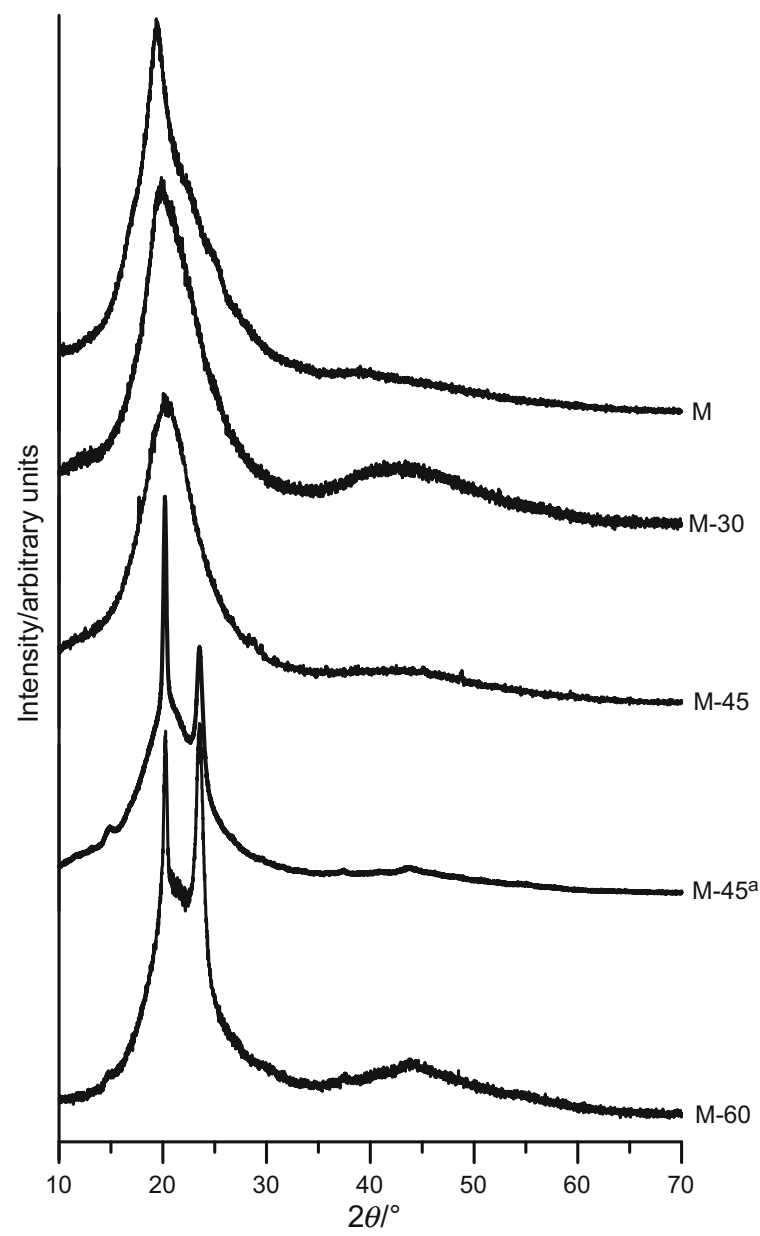

Fig. 11 XRD patterns of the polymers based on diol ME: RPUR M and PCURs after one-month conditioning (M-30, M-45 and M-60) and additionally after a 3 -month conditioning (M-45 ${ }^{\mathrm{a}}$ )

decomposition of the urethane linkages was attached to their dissociation to alcohols and isocyanates, followed by the carbodiimization of isocyantes and accompanied by the evolution of carbon dioxide. The decomposition of diarylsulfide linkages manifested by the evolution of carbonyl sulfide took place in the final phase of polymer

Table 6 XRD data of the polymers based on diol SE

\begin{tabular}{|c|c|c|c|c|c|c|c|c|c|c|c|c|c|c|c|}
\hline \multicolumn{4}{|c|}{ Degree of crystallinity/\% } & \multicolumn{4}{|l|}{$2 \theta /$} & \multicolumn{4}{|c|}{$\mathrm{FWHM}^{\circ}$} & \multicolumn{4}{|c|}{$\begin{array}{l}\text { Area of diffraction } \\
\text { peak/arbitrary units }\end{array}$} \\
\hline S & S-30 & S-45 & S-60 & $S$ & S-30 & S-45 & $S-60$ & $S$ & S-30 & S-45 & $S-60$ & $\mathrm{~S}$ & S-30 & S-45 & S-60 \\
\hline \multirow[t]{5}{*}{2.8} & 0.0 & 0.0 & 9.7 & 15.5 & 20.1 & 20.2 & 10.6 & 2.0 & 3.3 & 2.8 & 2.9 & 5 & 12 & 8 & 2 \\
\hline & & & & 18.7 & 22.0 & 21.5 & 20.2 & 3.1 & 7.6 & 7.5 & $0.4^{\mathrm{a}}$ & 29 & 100 & 100 & 8 \\
\hline & & & & 21.6 & 42.1 & 35.3 & 22.1 & $1.7^{\mathrm{a}}$ & 24.2 & 24.6 & 6.7 & 4 & 55 & 30 & 100 \\
\hline & & & & 21.6 & & & 23.5 & 9.6 & & & $0.7^{\mathrm{a}}$ & 100 & & & 10 \\
\hline & & & & 45.0 & & & 41.9 & 8.8 & & & 23.7 & 6 & & & 66 \\
\hline
\end{tabular}

\footnotetext{
${ }^{a}$ Crystalline peak
} 
Table 7 XRD data of the polymers based on diol ME

\begin{tabular}{|c|c|c|c|c|c|c|c|c|c|c|c|c|c|c|c|c|c|c|c|}
\hline \multicolumn{5}{|c|}{ Degree of crystallinity/\% } & \multicolumn{5}{|l|}{$2 \theta{ }^{\circ}$} & \multicolumn{5}{|c|}{ FWHM/ ${ }^{\circ}$} & \multicolumn{5}{|c|}{$\begin{array}{l}\text { Area of diffraction peak/arbitrary } \\
\text { units }\end{array}$} \\
\hline M & $\begin{array}{l}\text { M- } \\
30\end{array}$ & $\begin{array}{l}\text { M- } \\
45\end{array}$ & $\begin{array}{l}M- \\
45^{\mathrm{a}}\end{array}$ & $\begin{array}{l}\text { M- } \\
60\end{array}$ & M & $\begin{array}{l}\text { M- } \\
30\end{array}$ & $\begin{array}{l}\text { M- } \\
45\end{array}$ & $\begin{array}{l}\text { M- } \\
45^{\mathrm{a}}\end{array}$ & $\begin{array}{l}\text { M- } \\
60\end{array}$ & M & $\begin{array}{l}\text { M- } \\
30\end{array}$ & $\begin{array}{l}\text { M- } \\
45\end{array}$ & $\begin{array}{l}\text { M- } \\
45^{\mathrm{a}}\end{array}$ & $\begin{array}{l}M- \\
60\end{array}$ & M & $\begin{array}{l}\text { M- } \\
30\end{array}$ & $\begin{array}{l}\text { M- } \\
45\end{array}$ & $\begin{array}{l}\mathrm{M}- \\
45^{\mathrm{a}}\end{array}$ & $\begin{array}{l}\text { M- } \\
60\end{array}$ \\
\hline \multirow[t]{5}{*}{15.6} & 0.0 & 0.0 & 13.0 & 9.4 & 19.4 & 19.6 & 19.5 & 20.2 & 20.2 & $1.8^{\mathrm{b}}$ & 2.2 & 3.0 & $0.5^{\mathrm{b}}$ & $0.5^{\mathrm{b}}$ & 25 & 9 & 9 & 13 & 7 \\
\hline & & & & & 20.0 & 20.9 & 20.6 & 22.2 & 21.7 & 7.3 & 7.1 & 6.7 & 6.7 & 6.9 & 100 & 100 & 100 & 100 & 100 \\
\hline & & & & & 24.6 & 44.4 & 44.5 & 23.6 & 23.6 & 3.9 & 13.1 & 11.1 & $0.6^{\mathrm{b}}$ & $0.8^{\mathrm{b}}$ & 9 & 22 & 7 & 10 & 9 \\
\hline & & & & & 27.8 & & & 43.5 & 43.8 & 6.1 & & & 22.5 & 19.0 & 19 & & & 62 & 55 \\
\hline & & & & & 41.2 & & & & & 11.4 & & & & & 7 & & & & \\
\hline
\end{tabular}

${ }^{a}$ XRD data for a sample conditioned for 3 months at room temperature

b Crystalline peak

decomposition (starting at $420{ }^{\circ} \mathrm{C}$, maximum at $460{ }^{\circ} \mathrm{C}$ ). The presence of aliphatic ethers, aldehydes and alcohols was identified in the products of PCD decomposition. On the other hand, aldehydes can also originate from the decomposition of ether linkages in the hard segments.

FTIR spectrum recorded during the first decomposition stage $\left(T_{\max }\right.$ at $346{ }^{\circ} \mathrm{C}$ ) for PCUR M-30 (see Fig. 9) shows, besides bands shown for polymer S-30 in the first and second stages, absorption bands characteristic of carbonyl sulfide (with high intensity). It points to the fact that the decomposition of dialkyl-sulfide linkages occurred at much lower temperature (the start of carbonyl sulfide evolution at $295{ }^{\circ} \mathrm{C}$, maximum at $346^{\circ} \mathrm{C}$ ) than diaryl-sulfide ones. The analysis of volatile products of decomposition of the hardsegment-type RPUR M, presented in our earlier paper, showed that one may consider simultaneous decomposition of urethane and sulfide linkages occurring with the forming thiourethane intermediaries and followed by the elimination of carbonyl sulfide [12]. The presence of the same compounds as in the first stage, though only in minute amounts, was seen in volatile products from the second decomposition stage ( $T_{\max }$ at $435^{\circ} \mathrm{C}$; see Fig. 9).

\section{XRD analysis}

The XRD analysis was performed for all the synthesized PCURs after one-month conditioning at room temperature and additionally for polymer M-45 after 3 months as well as for RPURs $\mathrm{S}$ and $\mathrm{M}$. The received XRD patterns are presented in Figs. 10 and 11. The analysis of these patterns by the WAXSFIT program (see Tables 6,7) showed that among the PCURs, partially crystalline structures (degree of crystallinity in the range of 9.4-13.0 \%) were exhibited by those containing $60 \mathrm{~mol} \%$ soft segment (S-60 and M-60) as well as that containing $45 \mathrm{~mol} \%$ soft segment (M-45) after a longer conditioning. On the basis of the DSC curves (see Figs. 4, 5), it could be stated that their crystallinity resulted from the crystallization of PCD soft segment. A low tendency of RPURs to crystallization (degree of crystallinity amounting to $2.8 \%$ for $\mathrm{S}$ and $15.6 \%$ for M) explains the lack of the crystalline phase, which could be attributed to the crystalline hard-segment domains in the PCURs with a high hard-segment content. Figure 12 presents the plots received for selected polymers, i.e., $\mathrm{M}$, M-30 and M-60.

\section{Mechanical properties}

The Shore A/D hardness and tensile properties were determined for all the PCURs after a three-month conditioning at room temperature, and the numerical data are shown in Table 8.

The polymers based on diol SE showed hardness in the range of $76-90^{\circ} \mathrm{Sh} \mathrm{A}$ and $27-36^{\circ} \mathrm{Sh} \mathrm{D}$, while those based on diol ME possessed hardness in the range of lower values, i.e., $70-86^{\circ} \mathrm{Sh} \mathrm{A}$ and $27-32^{\circ} \mathrm{Sh} \mathrm{D}$. In the $\mathrm{M}$ series, it increased as the soft segment increased, whereas in the $\mathrm{S}$ series a different correlation was observed; the highest hardness was revealed by polymer S-60 and the lowest by S-45. The same relationships were found for the modulus of elasticity. PCURs based on diol ME with a longer aliphatic chain, the exception being M-45, were characterized by lower values of these parameters in comparison with the analogous polymers prepared from diol SE, with higher differences observed for those with the highest hard-segment content. The different behavior of polymer M-45 was due to the crystallization of PCD soft segment (see Fig. 5).

All the PCURs derived from diol SE exhibited higher tensile strength (33.5-41.9 vs. 27.0-31.5 MPa), but smaller elongation at break (300-400 vs. 450-550\%) than polymers from diol ME. Data presented in Table 8 show that a relatively good tensile strength, above $40 \mathrm{MPa}$, was achieved for polymers S-30 and S-45.

The PCURs synthesized by us exhibited better or much better tensile strength (with the exception of M-30), but lower hardness in comparison with analogous polymers obtained from aliphatic PCDs with $M_{\mathrm{n}} \sim 2000 \mathrm{~g} \mathrm{~mol}^{-1}$, MDI and BD as a chain extender [23]. 

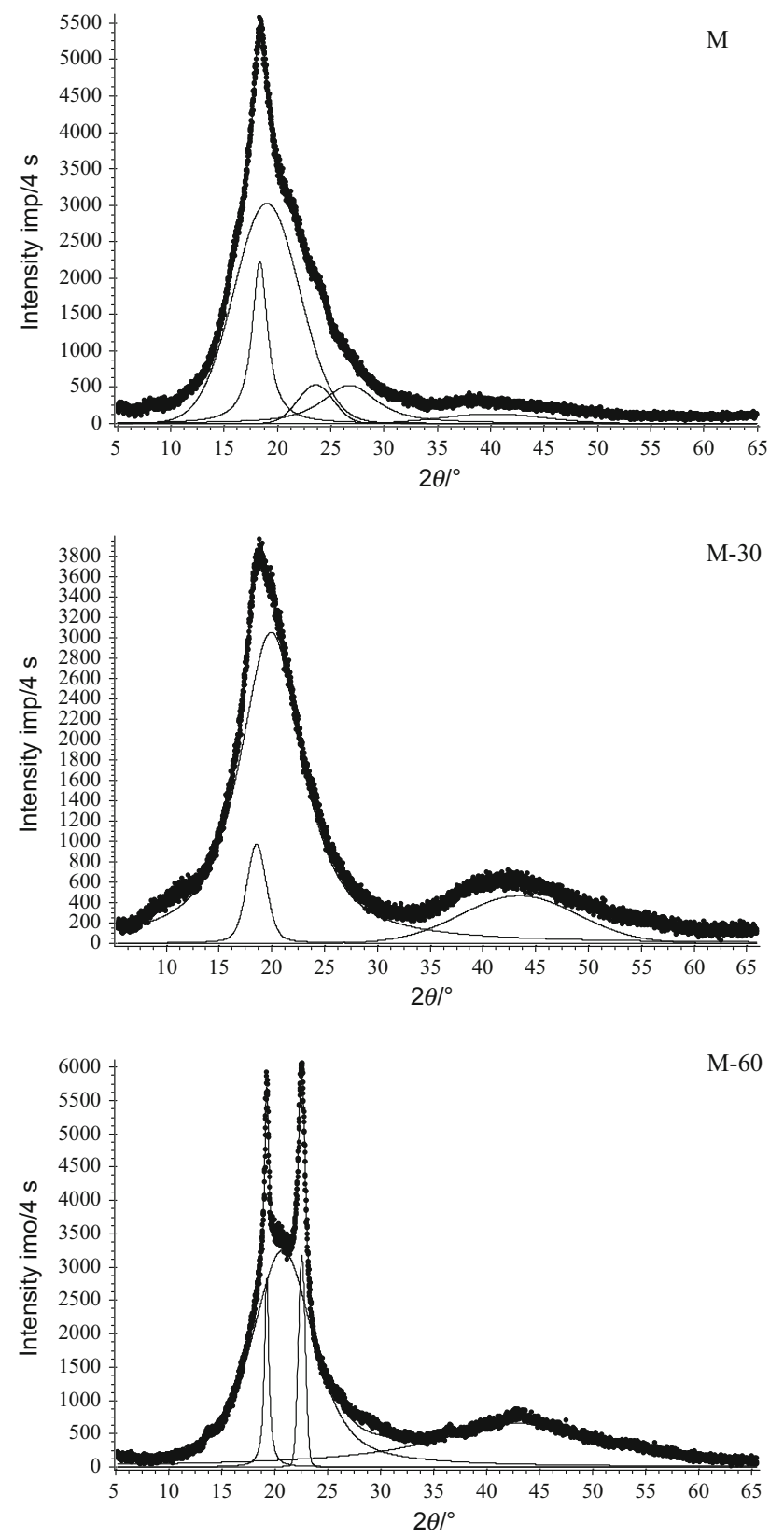

Fig. 12 XRD curves (points) of selected polymers resolved into crystalline and amorphous peaks (solid lines)

\section{Adhesive properties and refractive index}

The influence of the kind of the chain extender (different sulfur atoms content) on the lap shear strengths to copper (adhesion) and refractive index of the obtained PCURs was examined for polymers S-30 and M-30. Polymer M-30 based on diol ME with two sulfur atoms showed somewhat better adhesion (9.54 vs. $8.85 \mathrm{MPa}$ ) than polymer S-30 based on diol SE with one sulfur atom. Polymer M-30 also exhibited slightly higher refractive index (1.545 vs. 1.530).

\section{Conclusions}

Two series of high-molar-mass PCURs were synthesized from different nonconventional chain extenders, i.e., 2,2' [sulfanediylbis(benzene-1,4-diyloxy)]diethanol (diol SE) and 2,2'-[methanediylbis(benzene-1,4-diylmethanediylsulfanediyl)]diethanol (diol ME), MDI and 30, 45 and $60 \mathrm{~mol} \%$ aliphatic PCD of $M_{\mathrm{n}}=2000 \mathrm{~g} \mathrm{~mol}^{-1}$ via a onestep melt polyaddition. A DSC study showed that all the PCURs of $M$ series and two of $S$ series (S-45 and S-60) were TPUs. Lower $T_{\mathrm{g}} \mathrm{s}\left(-9\right.$ to $(-8)$ vs. -7 to $20{ }^{\circ} \mathrm{C}$ ) and better microphase separation were exhibited by the former PCURs. The two-phase morphology was confirmed by AFM. Taking into account the course of DSC curves, it can be said that the PCURs of both series showed a low tendency to forming ordered structures within hard-segment domains. The crystalline phase was found only for PCURs S-60, M-60 and, after a long storage, also for M-45 and was connected with the soft-segment crystallization, these polymers being opaque. The PCURs showed a relatively good thermal stability. Their $T_{1}$ were contained within the range of $284-292{ }^{\circ} \mathrm{C}$, and somewhat higher values were exhibited by those obtained from diol ME. The PCURs decomposed in two (from diol ME) or three (from diol SE) stages, and for both types of polymers, the main decomposition occurred at the first stage. On the basis of the analysis of the volatile decomposition products, it could be stated that the decomposition of a urethane linkage was connected with its dissociation to a diisocyanate and diol.

Table 8 Mechanical properties of the polymers

\begin{tabular}{|c|c|c|c|c|c|}
\hline \multirow[t]{2}{*}{ Polymer } & \multicolumn{2}{|c|}{ Hardness $/{ }^{\circ} \mathrm{Sh}$} & \multirow[t]{2}{*}{ Modulus of elasticity/MPa } & \multirow[t]{2}{*}{ Tensile strength/MPa } & \multirow[t]{2}{*}{ Elongation at break/\% } \\
\hline & $\mathrm{A}$ & $\mathrm{D}$ & & & \\
\hline S-30 & 85 & 34 & 14.8 & 40.7 & 300 \\
\hline S-45 & 76 & 27 & 7.02 & 41.9 & 370 \\
\hline$S-60$ & 90 & 36 & 18.0 & 33.5 & 400 \\
\hline M-30 & 70 & 27 & 4.14 & 31.5 & 450 \\
\hline M-45 & 82 & 29 & 14.5 & 27.0 & 500 \\
\hline M-60 & 86 & 32 & 17.6 & 31.1 & 550 \\
\hline
\end{tabular}


In the case of PCURs of M series, we should also consider mechanism generating carbonyl sulfide as the result of decomposition of the forming thiourethane intermediaries. TG-FTIR analysis showed that the decomposition of a dialkyl-sulfide linkage occurred at much lower temperature (over $100{ }^{\circ} \mathrm{C}$ ) than a diaryl-sulfide one. The PCURs of $\mathrm{S}$ series possessed higher tensile strength, but smaller elongation at break than polymers of $\mathrm{M}$ series. A relatively good tensile strength, above $40 \mathrm{MPa}$, was shown by polymers S-30 and S-45. Somewhat better adhesive properties and a slightly higher refractive index were found for polymer M-30.

Open Access This article is distributed under the terms of the Creative Commons Attribution 4.0 International License (http://crea tivecommons.org/licenses/by/4.0/), which permits unrestricted use, distribution, and reproduction in any medium, provided you give appropriate credit to the original author(s) and the source, provide a link to the Creative Commons license, and indicate if changes were made.

\section{References}

1. The polyurethanes book. Randall D, Lee S, editors. Everberg, Belgium: Huntsman Polyurethanes; New York: distributed by John Wiley \& Sons; 2002.

2. Wirpsza Z. Polyurethanes: chemistry, technology and applications. New York: Ellis Horwood; 1993.

3. Sonnenschein MF. Polyurethanes: science, technology, markets, and trends. New Jersey: Wiley; 2014.

4. Resiak I, Rokicki G. Modified polyurethanes for biomedical applications. Polim W. 2000;45:592-602.

5. Kojio K, Furukawa M, Motokucho S, Shimada M, Sakai M. Structure-mechanical property relationships for poly(carbonate urethane) elastomers with novel soft segments. Macromolecules. 2009;42:8322-7.

6. Liaw DJ. The relative physical and thermal properties of polyurethane elastomers: effect of chain extenders of bisphenols, diisocyanate, and polyol structures. J Appl Polym Sci. 1997;66:1251-65.

7. Padmavathy T, Srinivasan KSV. Studies on thermotropic main chain liquid crystalline segmented polyurethanes-1. Synthesis and properties of polyurethanes from high aspect ratio mesogenic diol as chain extender. J Macromol Sci, Polym Rev. 2003;C43:45-85.

8. Kultys A, Rogulska M, Pikus S. The synthesis and characterization of new thermoplastic poly(thiourethane-urethane)s. J Polym Sci A Polym Chem. 2008;46:1770-82.

9. Rogulska M, Kultys A, Olszewska E. New thermoplastic poly(thiourethane-urethane) elastomers based on hexane-1,6-diyl diisocyanate (HDI). J Therm Anal Calorim. 2013;114:903-16.

10. Kultys A, Puszka A. Transparent poly(thiourethane-urethane)s based on dithiol chain extender. Synthesis and characterization. J Therm Anal Calorim. 2014;117:1427-39.

11. Kultys A, Rogulska M, Pikus S, Skrzypiec K. The synthesis and characterization of new thermoplastic poly(carbonate-urethane) elastomers derived from HDI and aliphatic-aromatic chain extenders. Eur Polym J. 2009;45:2629-43.
12. Kultys A, Rogulska M, Pikus S. New thermoplastic segmented polyurethanes with hard segments derived from 4,4'-diphenylmethane diisocyanate and methylenebis(1,4-phenylenemethylenethio)dialcanols. J Appl Polym Sci. 2012;123:331-46.

13. Kultys A, Puszka A. New thermoplastic polyurethane elastomers based on sulfur-containing chain extenders. Pol J Chem Technol. 2013;15:1-6.

14. Kultys A, Podkoscielny W, Pikus S. Polyurethanes containing sulfur. I. New thermoplastic polyurethanes with benzophenone unit in their structure. J Polym Sci A Polym Chem. 1999;37:4140-50.

15. Rogulska M, Kultys A, Podkoscielny W. Studies on thermoplastic polyurethanes based on new diphenylethane-derivative diols. II. Synthesis and characterization of segmented polyurethanes from HDI and MDI. Eur Polym J. 2007;43:1402-14.

16. Rogulska M, Kultys A, Pikus S. Studies on thermoplastic polyurethanes based on new diphenylethane-derivative diols III The effect of molecular weight and structure of soft segment on some properties of segmented polyurethanes. J Appl Polym Sci. 2008;110:1677-89.

17. Rogulska M, Kultys A, Lubczak J. New thermoplastic polyurethane elastomers based on aliphatic-aromatic chain extenders with different content of sulfur atoms. J Therm Anal Calorim. 2015;121:397-410.

18. Rogulska M, Kultys A, Puszka A. New thermoplastic poly(carbonate-urethane)s based on chain extenders with sulfur atomsto be submitted for publication.

19. Penczek S, Frisch KC, Szczepaniak B, Rudnik E. Synthesis and properties of liquid crystalline polyurethanes. J Polym Sci A Polym Chem. 1993;31:1211-20.

20. Rabiej M, Rabiej S. Analysis of X-ray diffraction pattern of polymers by means of WAXSFIT computer program (in Polish). Poland: ATM; 2006.

21. Spirkova M, Poreba R, Pavlicevic J, Kobera L, Baldrian J, Pekarek M. Aliphatic polycarbonate-based polyurethane elastomers and nanocomposites. I. The influence of hard-segment content and macrodiol-constitution on bottom-up self-assembly. J Appl Polym Sci. 2012;126:1016-30.

22. Lee DK, Tsai HB, Tsai RS, Chen PH. Preparation and properties of transparent thermoplastic segmented polyurethanes derived from different polyols. Polym Eng Sci. 2007;47:695-701.

23. Eceiza A, Martin MD, de la Caba K, Kortaberria G, Gabilondo N, Corcuera MA, Mondragon I. Thermoplastic polyurethane elastomers based on polycarbonate diols with different soft segment molecular weight and chemical structure: mechanical and thermal properties. Polym Eng Sci. 2008;48:297-306.

24. Chattopadhyay DK, Webster DC. Thermal stability and flame retardancy of polyurethanes. Prog Polym Sci. 2009;34:1068-133.

25. Dunn JG, Chamberlain AC, Fisher NG, Avraamides J. The influence of activated carbon on the thermal decomposition of sodium ethyl xanthate. J Therm Anal Calorim. 1997;49:1399-408.

26. Fisher NG, Dunn JG. Analysis of a complex gaseous mixture by TG-MS and TG-FTIR. J Therm Anal Calorim. 1999;56:43-9.

27. Madarász J, Pokol G. Comparative evolved gas analyses on thermal degradation of thiourea by coupled TG-FTIR and TG/ DTA-MS instruments. J Therm Anal Calorim. 2007;88:329-36.

28. Simon J, Barla F, Kelemen-Haller A, Farkas F, Kraxner M. Thermal stability of polyurethanes. Chromatographia. 1988;25: 99-106.

29. Li SF, Zhi J, Yuan KJ, Yu SQ, Chow WK. Studies on the thermal behavior of polyurethanes. Polym Plast Technol. 2006;45:95-108. 